\title{
A Contabilidade Gerencial e a importância para a tomada de decisões nas organizações: Uma análise qualitativa
}

\author{
Management Accounting and its importance for decision making in organizations: A qualitative \\ analysis \\ La Contabilidad de Gestión y su importancia para la toma de decisiones en las organizaciones: Un \\ análisis cualitativo
}

Tarciara Magley da Fonseca Pereira ORCID: https://orcid.org/0000-0002-7570-8471 Universidade Potiguar, Brasil E-mail: tarciara@ufersa.edu.br

Rosianne Alexandre Gondim ORCID: https://orcid.org/0000-0001-9901-192X Centro Universitário Unirb, Brasil E-mail: roseconcret@gmail.com

Laís Karla da Silva Barreto ORCID: https://orcid.org/0000-0002-5267-5355 Universidade Potiguar, Brasil E-mail: laisbarreto@gmail.com

Fábio da Silva

ORCID: https://orcid.org/0000-0003-0039-0128 Universidade Potiguar, Brasil

E-mail: fabiosoyme@hotmail.com

Juliana Bianca Maia Franco

ORCID: https://orcid.org/0000-0002-7566-2688 Universidade Potiguar, Brasil

E-mail: juliana_franco_@hotmail.com

Kadja Kallyne Costa Barbosa

ORCID: https://orcid.org/0000-0002-3022-6583

Universidade Federal Rural do Semi-Árido, Brasil E-mail: kadjakallyne@ufersa.edu.br

Priscilla Even Alves Braga ORCID: https://orcid.org/0000-0003-4168-5571 Universidade Federal Rural do Semi-Árido, Brasil E-mail: priscilla@ufersa.edu.br

Maria de Fátima Santos Oliveira Duarte ORCID: https://orcid.org/0000-0001-6874-7707

Universidade Federal Rural do Semi-Árido, Brasil E-mail: fatimaduarte@ufersa.edu.br

Maria Helena da Costa Silva

ORCID: https://orcid.org/0000-0001-8716-8284

Universidade Federal Rural do Semi-Árido, Brasil

E-mail: helenacostacontabilidade@gmail.com

Luiz Eduardo Moura Barbalho

ORCID: https://orcid.org/0000-0002-2660-1037

Universidade Federal Rural do Semi-Árido, Brasil E-mail: luizeduardo@ufersa.edu.br

Kaliana Costa Batista

ORCID: https://orcid.org/0000-0003-3794-6062

Universidade Potiguar, Brasil

E-mail: kalianacosta@hotmail.com

Ádamo de Araújo Faustino

ORCID: https://orcid.org/0000-0002-5385-3272 Universidade do Estado do Rio Grande do Norte, Brasil E-mail: adamo@ufersa.edu.br

\section{Resumo}

As empresas no Brasil possuem a necessidade de uma contabilidade gerencial e eficaz voltados ao crescimento e/ou tomada de decisão. O objetivo geral desta pesquisa foi analisar como a Contabilidade Gerencial pode contribuir em tomadas de decisões das empresas. Metodologicamente, trata-se de uma análise bibliométrica por meio de uma revisão 
sistemática de literatura e qualitativa que se desenvolveu pela reunião de obras, como livros, Leis, artigos publicados. Este assunto é importante pelo fato de poder abranger o conhecimento nas empresas no que se refere ao seu planejamento financeiro e contábil. Sob o enfoque da gestão empresarial, observou-se o processo de gestão e avaliação de desempenho e a integração dos sistemas de informações gerenciais para tomadas de decisões assertivas. Foi analisado que a Contabilidade gerencial é uma ferramenta de suma importância para um trabalho bem elaborado para uma boa qualificação na tomada de decisões, desta maneira utiliza-se de análise de dados, redução de gastos, planejamento financeiros e preservação de desperdícios, visão econômica. Através dos resultados foi notório a necessidade e a importância de se utilizar as ferramentas na contabilidade gerencial dentro das empresas.

Palavras-chave: Contabilidade gerencial; Controle; Gestão.

\begin{abstract}
Companies in Brazil have the need for effective management accounting focused on growth and/or decision making. The general objective of this research was to analyze how Management Accounting can contribute to company decision making. Methodologically, it is a bibliometric analysis through a systematic literature and qualitative review that was developed by bringing together works, such as books, Laws, and published articles. This subject is important because it can cover knowledge in companies with regard to their financial and accounting planning. From the perspective of business management, the process of performance management and assessment and the integration of management information systems for assertive decision-making were observed. It was analyzed that management accounting is an extremely important tool for a well-designed job for a good qualification in decision making, in this way it uses data analysis, cost reduction, financial planning and waste preservation, economic vision. Through the results, the need and importance of using management accounting tools within companies was evident.
\end{abstract}

Keywords: Management accounting; Control; Management.

\title{
Resumen
}

Las empresas en Brasil tienen la necesidad de una contabilidad de gestión eficaz centrada en el crecimiento y / o la toma de decisiones. El objetivo general de esta investigación fue analizar cómo la Contabilidad de Gestión puede contribuir a la toma de decisiones de la empresa. Metodológicamente, se trata de un análisis bibliométrico a través de una revisión sistemática de la literatura y cualitativa que se desarrolló reuniendo trabajos, como libros, leyes y artículos publicados. Este tema es importante porque puede abarcar conocimientos en las empresas en lo que respecta a su planificación financiera y contable. Desde la perspectiva de la gestión empresarial, se observó el proceso de gestión y evaluación del desempeño y la integración de sistemas de información gerencial para la toma de decisiones asertiva. Se analizó que la contabilidad gerencial es una herramienta sumamente importante para un trabajo bien diseñado para una buena calificación en la toma de decisiones, de esta manera utiliza análisis de datos, reducción de costos, planificación financiera y preservación de residuos, visión económica. A través de los resultados, se evidenció la necesidad e importancia del uso de herramientas de contabilidad gerencial dentro de las empresas.

Palabras clave: Contabilidad de gestión; Control; Gestión.

\section{Introdução}

A conjuntura atual do mundo dos negócios evidencia um mercado de alto potencial competitivo, somado a isso uma ala consumidora cada vez mais exigente. Esse cenário é fruto, sobretudo, da influência da eminente progressão tecnológica, bem como do avanço da globalização, que faz com as empresas precisem ter uma posição estratégica satisfatória para atender as demandas e sobreviver nesse cenário. Sabendo disso, muitos estudos enfatizam a importância da gestão empresarial como fator determinante, pois, considera-se que para uma empresa conseguir se manter em expansão e de forma estruturada no mercado, é preciso que haja um planejamento estratégico e eficaz que garanta o seu desenvolvimento e sucesso.

A contabilidade desde sua criação, passou por grandes transformações, pois ela é essencial para qualquer empresa e vem se adequando constantemente às exigências do mercado. Hoje, a contabilidade deve ser tratada como uma grande aliada da gestão, especialmente em microempresas. Essas empresas costumam ser mais frágeis devido ao seu porte e no ambiente competitivo elas necessitam do amparo contábil para se manterem vivas devido à grande concorrência do mercado globalizado.

(Almeida Gomes, Monteiro \& Paulino, 2021).

Diante disso, uma ferramenta que vem sendo pontualmente referenciada como imprescindível nesse contexto, diz respeito à Contabilidade Gerencial, compreendida como área da Contabilidade responsável por produzir informações essenciais para a administração gerencial, haja vista reunir dados que são cruciais para atender diversos propósitos, tais como: auxílio no planejamento, na medida e avaliação de desempenho, na fixação de preços de venda e na análise de ações alternativas (Pizzolato, 
2000). Nesse norte, a Contabilidade Gerencial representa um braço forte na tomada de decisões em âmbito gerencial, por fornecer justamente uma gama de informações que podem alavancar a empresa no que tange ao alcance dos objetivos, à medida que a subsidia para que tenha vantagem competitiva e crescimento sustentável.

Sabe-se que muitas empresas chegam ao fim por não terem um suporte adequado que lhes norteie numa tomada de decisão segura, considerando todo o cenário do ramo em que se enquadra o negócio. Assim, por nem sempre possuírem conhecimentos necessários que auxiliem no controle gerencial e na movimentação operacional e financeira, a empresa tende a não acompanhar as mudanças e exigências do mercado, comprometendo seu desenvolvimento. Partindo então dessas premissas, o presente estudo tem como problemática norteadora o seguinte questionamento: Como a Contabilidade Gerencial pode contribuir na tomada de decisões das empresas?

Embora se trate de uma temática sempre em evidencia nos estudos contábeis, vê-se que é primordial levar essa discussão constantemente para âmbito acadêmico, porquanto é imprescindível que o futuro profissional da Contabilidade tenha plena noção da fundamentação e instrumentalidade dessa área da Contabilidade, qual seja, a gerencial, haja vista ser mais um ramo ao qual poderá atuar profissionalmente.

Além disso, pontua-se a relevância do debate para o próprio setor empresarial, já que se trata de uma ferramenta que tende a beneficiar diretamente na gestão das empresas, fomentando uma necessidade latente que gestores possuem de terem embasamento fidedigno e suficiente de informações que os oriente na tomada de decisão acertada e eficaz. O objetivo geral desta pesquisa foi analisar como a Contabilidade Gerencial pode contribuir em tomadas de decisões das empresas.

Com o avanço da tecnologia, as empresas utilizam diversos tipos de sistema da informação, que pode ser para uso operacional, financeiro, contábil etc. (Almeida Gomes, Monteiro \& Paulino, 2021). Em outras palavras, esses sistemas servem para transformar informações em dados que sejam úteis para as tomadas de decisões, e assim permitindo analisar a situação empresarial como um todo.

\section{Princípios de Contabilidade}

Com o intuito de compreender mais adequadamente a amplitude, em outras palavras, a área de abrangência dos Princípios de Contabilidade (PCs), é primordial apontar algumas considerações no contexto da etimologia da palavra princípios. As palavras de Franco (1997, p. 188) lecionam dizendo que "princípio é a causa da qual algo procede. É a origem, o começo de um fenômeno ou de uma série de fenômenos. [...] Verdade fundamental, evidente e inquestionavelmente comprovada". Ainda segundo o referido autor, podemos ver que "os princípios, quando entendidos como preceitos fundamentais de uma ciência são imutáveis, quaisquer que sejam as circunstâncias de tempo ou lugar em que uma doutrina é estudada" (Franco, 1997, p. 188).

Já segundo a concepção de Sá (2008, p. 91), podemos ver que "na fixação de normas de informação contábil os princípios são macro regras que orientam a tudo". Sendo assim, os princípios da contabilidade se apresentam como a fundamentação da contabilidade, isso porque são eles que apontam qual deve ser o caminho que vai ser seguido para alcançar aos objetivos que uma empresa deseja. As palavras de Marion et al (2003) agregam valor dizendo assim: Os princípios contábeis surgiram da necessidade da utilização de uma linguagem comum ao se preparar ou se interpretar adequadamente os relatórios contábeis (financeiros). Seria impossível aos usuários (acionistas, credores, clientes, governo etc.) desses relatórios interpretálos adequadamente, se cada contador estabelecesse seus próprios critérios em sua elaboração (Marion et al, 2003, p. 152).

Segundo a concepção de Iudícibus et al. (2009), os princípios contábeis são entendidos como conceitos básicos que administram a consecução da profissão contábil. Podendo ser ainda entendido como a forma, o meio e a estrutura com o intuito de alcançar os objetivos estipulado pela empresa.

O Conselho Federal de Contabilidade (CFC), por meio do artigo $2^{\circ}$ da Resolução 750/93, que sofreu uma alteração através da Resolução 1.282/10, determina que os princípios da contabilidade são a representação da essência das doutrinas e 
teorias associadas à contabilidade, se embasando na concepção predominante nos universos cientifico e profissional de todo o Brasil. Os estudos de Marion (2007), apontam que o objetivo da contabilidade é proporcionar todas as informações importantes com o intuito de que sejam tomadas as decisões dos usuários e, para tanto, faz uso da coleta de dados econômicos fazendo então a mensuração e registro dos dados com o formato de relatórios.

Os estudos de Iudícibus et al. (2010, p. 285) lecionam que os princípios contábeis são entendidos como as "premissas básicas acerca dos fenômenos e eventos contemplados pela contabilidade, premissas que são a cristalização da análise e observação da realidade econômica, social e institucional”. Segundo a concepção de Lopes \& Martins (2005), estes princípios devem orientar e gerar informações para os usuários, como os seguintes: Os princípios são o núcleo central da teoria contábil e estruturam a resposta da contabilidade aos seus desafios na busca de atingir os seus objetivos dentro do ambiente delimitado pelos postulados fundamentais. Assim, os princípios têm o papel de orientar efetivamente os procedimentos contábeis definindo a produção da informação (Lopes \& Martins, 2005, p. 129).

Sendo assim, a estrutura conceitual utilizada antes que apontava a existência de dois postulados, direcionada para uma visão da contabilidade que não ficava focada no usuário; atualmente, depois da Lei 11.638/07, o usuário se apresenta como o principal foco e, sendo assim, não existiam mais os postulados, mas sim os pressupostos (essência sobre a forma e a continuidade), que resultam em uma diferente concepção para poder encarar a contabilidade, depois da lei mencionada (BRASIL, 2007). Desta forma, a estrutura econômica e financeira do Planeta não possui mais delimitações, isso porque está totalmente interligada. Devemos ressaltar então que: A abordagem contextual retrata o ambiente globalizado, intenso em tecnologia, financeiramente interligado, volátil em suas percepções econômicas e sociais, buscando apresentar as respostas contábeis a toda essa nova demanda exigida desse novo cenário e as perspectivas dos avanços que se fazem necessários nos anos a seguir (Coelho \& Lins, 2010, p. 2).

Neste sentido, a criação dos órgãos internacionais não ocorreu, obrigatoriamente, nesse século, entretanto aconteceu por consequência das transformações econômicas e sociais. O IASC foi colocado em prática no ano de 1973 com o intuito de estipular a existência de um padrão de normas internacionais que tivesse a capacidade de ser praticado em um contexto internacional, podendo então fazer a emissão dos pronunciamentos contábeis denominados de IAS. No dia $1^{\circ}$ de abril de 2001, criou-se também o IASB, para substituir o IASC e assumir as suas responsabilidades técnicas.

Podemos apontar como sendo de grande relevância a criação, no ano de 2005, do CPC, através da Resolução 1.055/05 do CFC, possuindo este a intenção de fazer "o estudo, o preparo e a emissão dos Pronunciamentos Técnicos sobre procedimento de Contabilidade e a divulgação de informações dessa natureza" (PORTAL CONTABILIDADE, 2005). O início da utilização da contabilidade de custos está diretamente associado ao advento da Revolução Industrial, ao fim do século XVIII. Naquele momento, nascia a obrigatoriedade de se estipular o preço do produto final de forma financeira, em outras palavras, sendo então necessário fazer uma avaliação dos custos da transformação do insumo em um produto final. Procurando assim o ideal desenvolvimento desse processo, no século XX, a contabilidade de custos passou por um aperfeiçoamento através da técnica do fluxo de custo com taxas de rateio (Ferreira, 2007).

No decorrer dos anos, por conta do crescimento das organizações e da competitividade que existe no mercado, os gestores começaram a entender a contabilidade de custos como sendo uma ferramenta muito importante para o alcance de um gerenciamento eficiente. As palavras de Martins (2010, p. 21) lecionam que a "contabilidade de custos tem duas funções relevantes: o auxílio ao controle e a ajuda às tomadas das decisões". Consequentemente, ela conta com os objetivos de realizar o controle dos custos e a formação do preço do produto. Podemos ressaltar ainda que o sistema de informações gerenciais se fundamenta nas contabilidades financeira, de custos, gerencial e também pelo sistema orçamentário, constituindo assim uma ideia funcional das informações angariadas. Sendo assim, a contabilidade de custos, se fundamentando na concepção de Ferreira (2007), pode ser entendida como um processo de obtenção de custos e acaba dependendo do armazenamento das informações, 
entretanto, a característica mais relevante da contabilidade de custos deve ser apontada como os procedimentos que são utilizados para que se identifiquem todos esses dados.

\section{Contabilidade e Gestão Empresarial na Tomada de Decisões}

A gestão empresarial como aponta Stoner \& Freemann (1985, p. 5) é a forma de "planejar, organizar, liderar, e controlar os esforços realizados pelos membros da organização e o uso de todos os outros recursos organizacionais para alcançar os objetivos estabelecidos". Assim, se percebe que é preciso ter alguém, que lidere, organize, prepare as pessoas para que possam dar o máximo de si e assim, engrenar o sistema para que se utilizem os recursos da melhor forma, sem desperdícios e promovam os resultados esperados. Portanto, cabe ao administrador focar as ações para o desenvolvimento e fazer com que as coisas aconteçam por meio das pessoas de sua organização, entidade, órgão ou empresa a que está inserido. A observação crítica dos conceitos acima nos revela a importância que a administração tem.

A tomada de decisão é umas das funções da contabilidade, pois de acordo com Garrison \& Noreen (2001), já que ela está sempre se deparando com questões do tipo: quais produtos vender, quais métodos de produção empregar, fabricar ou comprar, qual preço cobrar, quais canais de distribuição, quando aceitar pedidos especiais, etc. Azevedo (2016, p. 11) a gestão empresarial é muito dinâmica, os resultados que a empresa obteve no passado, não garantem por si só novos resultados em um ambiente competitivo, no ponto de vista do autor é necessário que a empresa tenha organização e controle eficientes para resolver os problemas de gestão.

Na perspectiva de Azevedo (2016, p. 1), no atual cenário empresarial, deve-se considerar: exponencial desenvolvimento tecnológico, o processo de evolução da economia e o crescimento das organizações tornaram o ambiente complexo, dificultando a gestão dos negócios. Levando-se em consideração que a informação é fundamental para o processo de gestão, os controles gerenciais passaram a ocupar posição de destaque na pauta de prioridades dos executivos. $\mathrm{O}$ autor destaca ainda que "o controle gerencial deve assegurar que os resultados das operações se aproximem dos objetivos estabelecidos". Para que haja a asseguração, os controles precisam estar dispostos em pontos estratégicos: antes que a operação seja totalmente completada; durante a ação, através de paradas para testes e inspeções, aprovando ou não a continuidade operacional; ou após a realização dos trabalhos, gerando o processo de "feedback". É importante destacar que a ausência e/ou falha no controle gerencial de previsões e acompanhamento das operações e a indevida avaliação do risco constituem características negativas de uma empresa moderna.

\subsection{Elaboração do Plano}

Os estudos de Michael Porter, no ano de 1990, dão mais força ao argumento de que o desempenho além da média em uma organização pode ser atingido e mantido através de uma estratégia competitiva, referindo-se sobre um tipo de benefício que a organização possui quando comparada aos concorrentes, acompanhando e evoluindo sobre o mercado onde está introduzida. Em conformidade com Oliveira, Perez Jr. \& Silva (2014, p. 32), a sequência para a elaboração do plano compreende:

a) A determinação da missão da empresa;

b) A análise ambiental, que inclui: A identificação dos fatores-chaves de sucesso; A análise das variáveis ambientais críticas internas e externas;

c) O estabelecimento de diretrizes e objetivos estratégicos;

d) A determinação de estratégias;

e) A avaliação dessas estratégias. 
Sendo assim, a competição existe no momento em que existe uma disputa por algo que dois ou mais competidores pleiteiam. Desta forma, são diversas as espécies de competições que ocorrem no dia a dia da empresa. A competição econômica pode ser vista em um ambiente que é conhecido como um sistema concorrencial, e através deste as duas ou mais organizações disputam mais pela sobrevivência no mercado do que pela própria procura pelo maior lucro possível. Desta forma, a estratégia competitiva possui um espaço de extrema relevância e muito decisivo para o sucesso da empresa, se equiparando ao sucesso empresarial pode construir ou renovar os seus potenciais de competição. Este referido potencial pode ser moldado através da capacidade da empresa em analisar o mercado por meio de um ângulo diferente, e o sucesso está associado com a consecução da estratégia adequadamente estipulada, começando assim a gestão estratégica no planejamento empresarial.

\subsection{Modelo de Gestão}

O Processo de Gestão está intimamente ligado com todas as áreas dado que é estruturado a partir da missão, crenças e valores da empresa e pode assumir diversos formatos dependendo da realidade de cada instituição. O processo de gestão serve de suporte ao processo de tomada de decisão e realiza-se a partir das fases de planejamento, execução e controle. Segundo entendimento de Catelli (2015, p. 58) o processo de gestão é decorrente do modelo de gestão. O processo decisório deve assegurar que as decisões que são tomadas na empresa estejam de acordo com a missão, garantindo equilíbrio e continuidade. $\mathrm{O}$ autor afirma que o processo de gestão deve: "ser estruturado com base na lógica do processo decisório; contemplar, analiticamente as fases de planejamento, execução e controle das atividades da empresa; ser suportado por sistemas de informações que subsidiem as decisões". No quesito planejamento o autor menciona a divisão em: "pré-planejamento, planejamento de médio/longo prazos e planejamento de curto prazo. E define que:

O processo de gestão econômica estrutura-se nas fases de planejamento estratégico, planejamento operacional, execução e controle, contemplando um conjunto de definições básicas sobre os objetivos, os produtos e os requisitos de cada uma dessas fases. Nascimento \& Reginato (2013) apontam que o modelo de gestão precisa ser um facilitador e um orientador do processo de gestão, através de determinadas características, e o sucesso ou insucesso da ação organizacional é determinado em função: da conduta, do moral e do comportamento das pessoas; da influência dos grupos informais; da determinação de responsabilidade e autoridade; do sistema de informações; e dos critérios de avaliação de desempenho. Os sistemas de planejamento constituem importante ferramenta aos administradores proporcionando o levantamento de dados sob o funcionamento e gerenciamento da organização. Através do sistema de custos é possível gerar relatórios com informações financeiras, com dados operacionais e outros indicadores.

No campo da gestão do negócio é fácil de encontrar termos de planejamento e programação relacionados com sistema de planejamento, programação e controle. Este sistema faz parte do sistema de gestão e controle que, em conjunto com o sistema de gestão e organização, constituem a fundamentar tripartição da doutrina de gestão empresarial. A administração da empresa também é conduzida pelo Planejamento Financeiro, uma vez que este permite acompanhar e rever, quando necessário, as diretrizes de mudança, bem como reavaliar as metas já estabelecidas.

Assim, possibilita que a administração visualize com antecedência:

$>\quad$ Os níveis de investimento;

$>\quad$ Montante de dívida da organização;

$>\quad \mathrm{O}$ montante do capital de giro;

$>\quad$ O percentual de crescimento no longo prazo;

$>\quad$ A rentabilidade atual e futura (Gitman, 2004). 
O modelo de gestão que uma empresa segue refletirá diretamente no desenvolvimento do negócio. A determinação do modelo de gestão é resultado da missão estabelecida, dos propósitos e objetivos que se almeja. Oliveira, Perez Jr \& Silva (2014, p. 109) tecem através de um exemplo prático, o passo-a-passo de um modelo:
1. Situação atual da empresa
2. Situação atual diagnosticada
3. Situação atual real
4. $\quad$ Sistemas de informações gerenciais
5. Situação futura
6. Situação futura prognosticada
7. Situação futura desejada
8. Situação futura planejada
9. Planejamento estratégico
10. Orçamento empresarial integrado
11. Apuração de situação futura projetada
12. Comparação da situação futura projetada com a planejada
13. Avaliação e aprovação
14. Execução
15. Mensuração da execução
16. Apuração da situação real da empresa
17. Comparação da situação real com a originalmente projetada

Os autores afirmam que é preciso ter uma visão sistêmica quanto ao modelo de gestão. Deve-se considerar a empresa como um sistema aberto, com subsistemas e processos que interagem entre si e com o ambiente externo. Essa concepção é fundamental também para o planejamento estratégico, pois pode-se enxergar as relações entre os elementos internos e externos, e ainda caracterizam os elementos do sistema da seguinte forma: Na concepção de Prestes (2002) em se tratando de formatação de um modelo, o administrador deve fazê-lo de forma tal que considere o cenário econômico que a empresa está inserida ou passe por uma reestruturação organizacional que permita que o modelo: absorva a capacidade de produção instalada; agregue valor aos processos e produtos; otimize a quantidade de recursos financeiros, pessoal e material; e utilize a tecnologia da informação disponível com maior precisão e qualidade para obter-se um altíssimo giro operacional.

Em Nascimento \& Reginato (2013, p. 41) tem-se o apontamento destacado para as pessoas, pois são elas que atuam para atingirem os objetivos da organização de forma coordenada. Com isto, dá-se o mérito da gestão para a combinação dos objetivos por meio de seu processo de "planejar, executar e controlar de forma a otimizar desempenho e maximizar resultados". Os autores destacam ainda que o que diferencia os resultados das empresas seja o formato do modelo de gestão e a forma com que o processo de gestão é influenciado nas decisões em uma determinada entidade, mesmo que as empresas tenham o mesmo porte e área de atuação, com condições operacionais semelhantes, ou seja, o modelo de gestão que está implícito ou explícito no comportamento dos indivíduos e no conjunto das pessoas refletirá nas decisões a serem tomadas.

Para os autores, o ambiente - interno e externo - é formado por agentes que tem objetivos próprios e diferentes, que formam uma relação complexa. Nascimento \& Reginato (2013) abordam o aspecto formal da organização que é composto pelos seus elementos, retratam ainda que a relação sistema-empresa exige certo grau de flexibilidade para que se adaptem as variações que ocorrem no ambiente, através de ações organizadas de acordo com as teorias administrativas (clássica e administrativa): 
tarefa; estrutura; pessoas; pessoas formadoras da cultura organizacional; e a tecnologia. Os elementos organizacionais integrados mantêm a empresa competitiva no mercado.

Para que se entenda como ocorre o processo de tomada de decisão e como contribui para a eficácia, deve-se entender qual missão da empresa. A missão é o verdadeiro sentido de a empresa existir, e é através da missão que a empresa se posicionará no mercado. Por esse motivo, a declaração deve ser precisa, fidedigna, objetivos e detalhados. Uma declaração vaga pode fazer com que os gestores tomem decisões contrárias aos propósitos pelos quais são norteados. Desse modo, funcionará como elemento balizador de como a missão será atingida, gerando limites pelos quais as decisões dos gestores não sejam conflitantes com a vontade dos donos do negócio (Schmidt, Santos \& Martins, 2014).

No que se refere à implementação, é necessário estabelecer a missão, visão e objetivos estratégicos já indicados no Planejamento Estratégico, e segundo os autores, é o momento onde fica mais evidente e intensa a área de controladoria, "que consiste em medir os resultados a partir do modelo implementado". Para se traduzir a estratégia em medidas considera-se os seguintes princípios: "relações de causa e efeito; os vetores de desempenho; e a relação com os fatores financeiros."

O BSC tem o propósito de viabilizar os seguintes processos gerencias críticos: "esclarecer e viabilizar a visão e a estratégia; comunicar e associar objetivos e medidas estratégicas; planejar, estabelecer metas e alinhar iniciativas estratégicas; melhorar o feedback e o aprendizado estratégico". (Nascimento \& Reginato, p. 250)

Através do entendimento do BSC podemos afirmar que o objetivo do sistema de mensuração motiva aos envolvidos no processo a executarem com sucesso a estratégia da empresa ou unidade de negócio (Nascimento \& Reginato, p. 251).

As crenças e valores são os elementos geradores da real missão da entidade, sendo imprescindível que seja entendido por todos, sob o risco de sair do rumo de seu processo decisorial. Através do entendimento da missão, as crenças e valores participam efetivamente na composição do modelo de gestão. (Schmidt, Santos \& Martins, 2014).

Para Oliveira, Perez Jr \& Silva (2014, p. 105) as crenças não são dogmáticas, pois refletem as características e propriedades demonstradas pelos proprietários, isso pode dificultar a compreensão pelos funcionários. Ponderações quanto ao meio ambiente, qualidade, ética e respeito são alguns exemplos de fatores que impactam todas as decisões futuras em todos os níveis organizacionais e reflete as crenças e valores nos quais o dirigente considera.

\subsection{Controle como Modelo de Gestão}

Chiavenato (2003, p. 176) afirma que, "o processo de controle é um modelo de gestão utilizado pelos administradores, e tem como finalidade confirmar que os resultados do que foi planejado alcançou os objetivos estabelecidos". O Controle é a função que agrega as funções da administração. Nesse ciclo o planejamento estabelece os objetivos da organização e o controle averigua se os objetivos estão sendo praticados de acordo com o planejamento. O controle observa o comportamento segundo o planejamento, em relação aos objetivos e preceitos que foram elaborados previamente. Na visão de Martins (2010, p. 306) "controlar significa conhecer a realidade, compará-la com o que deveria ser, tomar conhecimento rápido das divergências e suas origens e tomar atitudes para sua correção".

Nascimento \& Reginato, apresentam uma imagem que expõe as dimensões do controle organizacional: Assim como pode se observar, os autores destacam que a visão dimensional do controle é instituída com base no modelo de gestão, que "se fundamenta nas crenças e valores dos líderes da empresa e em sua percepção". No dizer dos autores, o sistema de controles internos é influenciado pelo ambiente de controle, isto é, pela organização formal em si, pela atitude e compromisso da administração e dos funcionários, pelos métodos e avaliação e gerenciamento de riscos. Esse ambiente é quem tornará promissor ou não a implantação e execução dos procedimentos de controle. O controle organizacional em sua forma plena reflete os meios utilizados pela administração para criar padrões de comportamento a serem seguidos pelos membros organizacionais, de forma que estes levem o empreendimento a eficácia, e que sirvam de base para o seu próprio monitoramento, utilizando-se 
procedimentos apropriados de gestão, entre eles o planejamento, considerado um instrumento macro de controle. (Nascimento \& Reginato, 2013, p. 3).

Ao referir-se a controle, Catelli (2015, p. 171) sustenta que para que haja um desempenho eficaz da função controle é imprescindível ter um sistema de informação eficiente, na qual mostrará a necessidade de ações corretivas, deixando viável aos gestores julgar se seus objetivos pertinentes ou não, em razão das alterações no ambiente interno ou externo. $\mathrm{O}$ autor ainda se utiliza da seguinte argumentação: A função controle está intimamente ligada a função planejamento por meio do sistema de feedback que fornece informações sobre o resultado das informações passadas. Tal sistema é necessário para avaliar a qualidade do processo decisório e seus aprimoramentos. Azevedo (2016) a presença de controles eficazes é uma exigência das empresas modernas, na qual as informações devem ser confiáveis e os controles devem ser exercidos sob o enfoque gerencial, tornandose assim elementos vitais para embasar as decisões a serem tomadas.

\subsection{Controle e Avaliação dos Resultados}

A utilização de orçamentos como instrumento de gestão empresarial deve ser vista notoriedade para o controle e avaliação dos resultados a serem alcançados pelas operações planejadas, sendo, desta forma, uma ferramenta imperativa para assegurar o processo de tomada de decisão. Nesse sentido, Nascimento \& Reginato (2013, p. 158) afirmam que: Os produtos do planejamento devem ser as clássicas demonstrações financeiras, isto é, balanço patrimonial, demonstração de fluxo de caixa e demonstração de resultados, além do plano de investimentos, as quais devem ser analisadas sob duas diferentes perspectivas: a da alta administração e a dos gestores operacionais.

Sob a perspectiva da alta administração, o planejamento é capaz de mostrar uma visão completa dos ativos, passivos e fluxo de caixa, de onde pode se extrair indicadores que são utilizados para nortear a gestão da empresa. Os autores relatam também as vantagens da adoção do orçamento:

a) Disciplina quanto ao nível de gastos compatível com o resultado econômico esperado;

b) Visibilidade;

c) Definição de responsabilidade de gestores;

d) Avaliação de desempenho;

e) Instrumento de validação da estratégia.

f) No que se refere às desvantagens da adoção de orçamento, os autores destacam os seguintes pontos:

g) Se elaborado com premissas erradas, ele pode induzir a decisões equivocadas;

h) Os orçamentos podem conter gorduras nele introduzidas pelos gestores, no sentido de se pouparem da necessidade de explicação para desvios negativos;

i) Se utilizado como mecanismo de avaliação de desempenho dos gestores, o orçamento pode ser estimulante para que se pratique a administração criativa, na qual receitas e despesas podem ser administradas de acordo com a conveniência, estimulando conflitos de agência;

j) Sem um controle forte, pode ser apenas um instrumento pro forma, o que implica contraírem custos administrativos;

k) A principal desvantagem é que se traça uma trajetória da empresa a partir de uma fotografia construída por meio de uma análise subjetiva das variáveis ambientais.

A propósito, os autores também afirmam que há um paradoxo no meio empresarial, visto que caso não haja um planejamento adequado, o crescimento e lucro podem configurar em fracasso a médio e longo prazo. Dito isto, mesmo que a empresa obtenha lucros, mas se não tiver a capacidade de gerar caixa no momento adequado, isso pode ocorrer. Por este motivo, 
é imprescindível que haja conciliação dos prazos de realização dos ativos com os prazos de exigibilidade das fontes de financiamento.

Nascimento \& Reginato (2013, p. 172) mencionam que "o orçamento, para a área de controladoria, é o principal instrumento de acompanhamento das operações”. Em seguida, os autores nos esclarecem algumas premissas básicas a serem consideradas durante a elaboração do orçamento, isto é, os indicadores de gestão, que permite o equilíbrio operacional, econômico e financeiro, que são eles: prazo médio de recebimento de vendas, pagamento de fornecedores e giro de estoques, projeção de receita e custos e os investimentos.

\subsection{Controle Orçamentário e Financeiro}

Para este tópico, cabe a excelente elucidação de Matz, Curry \& Frank (apud Braga 1991, p. 231) que trata da relevância do orçamento como guia para a empresa e seus gestores: Todo homem de empresa segue, em maior ou menor grau, os princípios orçamentários quando prevê operações e receitas e quando planeja programas de produção, crédito e vendas. Mas orçar é mais do que tudo isso. Orçar é um meio de coordenar a inteligência combinada de toda uma organização em um plano de ação, baseado na experiência anterior e governado por juízo racional de fatores que exercerão influência sobre o curso dos negócios no futuro. Orçar não é apenas controle, não é apenas previsão. É uma análise exigente e rigorosa do passado e um cálculo cuidadoso das prováveis e desejadas operações futuras. O objetivo é colocar o julgamento deliberado, bem concebido e astuto dos negócios em lugar do êxito acidental na administração do empreendimento.

Não se deveria considerar o orçamento como expressão daquilo que se acredite que venha a ocorrer, mas, ao contrário, deve-se considerá-lo como objetivo realizável. É uma bússola pela qual uma empresa pode manter-se tão perto quanto possível do curso traçado. Um orçamento compele os executivos a estudar seus problemas. Instila o hábito da investigação cuidadosa antes que se tomem as decisões. Uma vez completados os estudos e tomadas várias decisões, o orçamento servirá como uma declaração de princípios, baseada nos esforços conjuntos de todos os interessados. A partir desta proposição, podemos entender o engajamento do controle orçamentário e financeiro para com a gestão empresarial. De acordo com Azevedo (2016) o orçamento não deve ser visto apenas como um instrumento de um sistema global, fazendo parte apenas do planejamento, mas sim como peça de destaque para o controle e avaliação da performance a ser atingida pelas operações planejadas, o que poderá resultar em criação de valor para o proprietário da empresa. Caso o planejamento seja bem elaborado, levando-se em conta as diversas varáveis pertinentes à sua elaboração, um orçamento não cumprirá sua finalidade caso não seja possível exercer controle efetivo sobre os resultados projetados.

Em Welsch (1986) encontra-se que o controle de resultados pode ser definido, em termos amplos, como um enfoque sistemático e formal à execução das responsabilidades de planejamento, coordenação e controle da administração. Quanto ao controle financeiro, Azevedo (2016) diz que se destina a assegurar a obtenção de recursos e o seu emprego de forma eficaz e eficiente possa atingir os objetivos da organização, fazendo parte do sistema total de controle gerencial. Na concepção do autor "os objetivos de um sistema de controle financeiro são a comunicação, a avaliação e a motivação". Quanto ao sistema formal de controle financeiro, reconhece quatro elementos básicos: definição de objetivos; formulação de planos; medição de resultados; e comparação dos resultados com os objetivos.

\subsection{Planejamento Financeiro de Longo Prazo}

Segundo as palavras de Gitman (2004), podemos entender o planejamento financeiro de longo prazo da seguinte maneira: Os planos financeiros a longo prazo são ações projetadas para um futuro distante, acompanhado da previsão de seus reflexos financeiros. Tais planos tendem a cobrir um período de dois a dez anos, sendo comumente encontrados em planos quinquenais que são revistos periodicamente à luz de novas informações significativas (Gitman, 2004, p. 588). 
Sendo assim, podemos ver que os planos financeiros de longo prazo se apresentam como uma maneira organizada e sistemática, através do qual são evidenciadas as necessidades de capital ou financiamento com o intuito de fazer com que as aspirações da empresa se tornem realidade. O planejamento financeiro de longo prazo ajuda então na ordenação das possíveis alternativas, priorizando assim os objetivos e direcionam as ações da empresa.

Os estudos de Ross, Werterfield \& Jordam (1998) apontam que a real intenção do planejamento financeiro de longo prazo é a de estipular quais são as diretrizes para alterações necessárias para a empresa e essas diretrizes precisam contar com três diferentes princípios, vejamos:
I - Identificação dos objetivos financeiros da empresa;
II - Análise entre as metas e a situação corrente da empresa;
III - Um enunciado das essenciais ações para que a empresa possa alcançar as suas metas financeiras.

Sendo assim, os planos de longo prazo, pela concepção de Gitman (2004, p. 588), devem ficar focados nos "dispêndios de capital, atividades de pesquisa e desenvolvimento, ações de marketing e de desenvolvimentos de produtos, estrutura de capitais e importantes fontes de financiamentos".

Grande parcela das empresas possui como elemento essencial de seu planejamento financeiro de longo prazo uma taxa de crescimento global e muito clara. Dessa forma, existe uma interação direta entre a taxa de crescimento e também a sua política financeira (Ross, Werterfield \& Jordam, 1998). A inexistência de um planejamento financeiro a longo prazo eficiente é a razão de maior importância para o surgimento de dificuldades e falências de empresas. Os planos financeiros em longo prazo apresentam uma tendência de se fundamentarem em planos financeiros a curto prazo e se associam com um planejamento estratégico da organização.

\subsection{Planejamento Financeiro de Curto Prazo}

As palavras de Gitman (2004, p. 588) lecionam ainda que "os planos financeiros de curto prazo são ações planejadas para um período curto (de um a dois anos) acompanhado da previsão de seus reflexos financeiros”. Já os dizeres de Brealey \& Myers (1998) lecionam assim sobre o assunto: O planejamento financeiro de curto prazo preocupa-se com gestão do ativo a curto prazo, ou circulante, e do passivo de curto prazo da empresa. Os elementos mais importantes do ativo circulante são as disponibilidades, os títulos negociáveis, as exigências e as contas a receber. Os elementos mais importantes do passivo de curto prazo são empréstimos bancários e as contas a pagar (Brealey \& Myers, 1998, p. 839).

As pesquisas feitas por Ross, Werterfield \& Jordam (1998, p. 607), apontam que, entre as diversas políticas de financiamento a curto prazo, precisam levar em consideração os seguintes fatores: a) Reservas de Caixa: a estratégia flexível de financiamento implica a existência de superávits de caixa e praticamente nenhuma necessidade de captação a curto prazo, reduzindo a probabilidade de dificuldades financeiras para a empresa; b) Casamento de Prazos de Vencimento: muitas empresas financiam estoques com empréstimos bancários a curto prazo e os ativos imobilizados com recursos a longo prazo. Procura-se evitar o financiamento de ativos de longa duração com recursos de curto prazo; c) Estrutura Temporal de Juros: as taxas de juros a curto prazo normalmente são inferiores às taxas a longo prazo (Ross, Werterfield \& Jordam, 1998, p. 607).

Cabe apontar ainda que as metas de maior relevância que um planejamento de curto prazo deve contar é a previsão de vendas em conjunto com as informações operacionais e financeiros. Como uma consequência da realização de uma análise do planejamento de curto prazo apresenta como relevante elemento os orçamentos operacionais, "orçamento de caixa e demonstrações financeiras projetadas" (Gitman, 2004, p. 588). 


\section{Tomada de Decisão da Contabilidade de Custos}

A tomada de decisão é umas das funções da contabilidade de custos, pois de acordo com Garrison \& Noreen (2001), já que ela está sempre se deparando com questões do tipo: quais produtos vender, quais métodos de produção empregar, fabricar ou comprar, qual preço cobrar, quais canais de distribuição, quando aceitar pedidos especiais, etc.

Azevedo (2016, p. 11) a gestão empresarial é muito dinâmica, os resultados que a empresa obteve no passado, não garantem por si só novos resultados em um ambiente competitivo, no ponto de vista do autor é necessário que a empresa tenha organização e controle eficientes para resolver os problemas de gestão.

Na perspectiva de Azevedo (2016, p. 1), no atual cenário empresarial, deve-se considerar: exponencial desenvolvimento tecnológico, o processo de evolução da economia e o crescimento das organizações tornaram o ambiente complexo, dificultando a gestão dos negócios. Levando-se em consideração que a informação é fundamental para o processo de gestão, os controles gerenciais passaram a ocupar posição de destaque na pauta de prioridades dos executivos.

\subsection{Ações da Gestão de Custos e de Resultado}

Todos os dias as empresas precisam ir se adequando às alterações ocorridas no mercado, que está a cada dia mais competitivo. Desta maneira, o sistema de custeio se transforma em um elemento essencial para todos os tipos de empreendimentos, levando em consideração que o gestor faz a opção por ficar focado principalmente nos setores com maiores déficits, e através desta análise dos custos é capaz de fazer a identificação de quais são. Entretanto, o que podemos entender por custos? Segundo as palavras de Martins (2010, p. 23), podemos ver que "são os gastos que vão ser utilizados para desempenhar a atividade fim da empresa".

Com o intuito de fazer uma análise sobre o custo, é preciso usar os métodos de custeio, que podem ser classificados através dos estudos de segundo Garcia (2010), tendo duas opções. A primeira é um procedimento de custeio por absorção, compreendendo que aqui devem ser considerados todos os custos em suas fases de produção. Já no tocante do método de custeio direto ou variável, devendo este usar com o intuito de definir o custo apenas com os diretos e variáveis, os outros devem ser entendidos como despesas, no resultado. Por meio do uso dos métodos para o custeio deverá fazer a identificação de qual deve ser o custo de uma unidade do produto vendido, desta forma, o gestor se fundamenta adequadamente para que se forme de forma correta o preço de venda deste produto. Diferentes e relevantes conceitos que precisam ser averiguados são o ponto de equilíbrio, margem de contribuição, margem de segurança e ainda a alavancagem operacional. Todas estas informações sobre a análise gerencial podem ajudar relevantemente para o alcance do sucesso de uma empresa, proporcionando assim dados extremamente importantes para que sejam tomadas as decisões.

\subsection{Ações para a Análise e Gestão Financeira}

Podemos ver que análise financeira pode ser usada com a finalidade de fazer o adequado controle da empresa e proporcionar uma correta tomada de decisão dos seus gestores. Por meio deles a organização pode dimensionar o quanto será capaz de gastar e se irá possuir capital o bastante para investimento. Desta forma, a ferramenta de maior relevância para o controle financeiro é denominada como fluxo de caixa, sendo extremamente importante tê-lo, especialmente com o intuito de ter correto conhecimento sobre o fluxo de dinheiro cotidiano da organização. O processo de elaboração do fluxo de caixa precisa englobar o saldo inicial do dia, entradas e saídas, e também o saldo final do caixa diário; simples e eficiente.

O referido procedimento de análise fundamenta a informação através do balanço patrimonial da instituição, se embasando na realização de uma comparação das contas contábeis para chegar à conclusões sobre a situação econômicofinanceira da organização. Sendo importante ainda fazer uma análise incessante sobre uma demonstração após um ano de funcionamento da empresa, com o intuito de possuir maior exatidão dos resultados que são analisados. 
Desta forma, os índices de liquidez evidenciam a capacidade que a empresa possui de fazer o pagamento de suas dívidas a curto e longo prazo. Evidenciam ainda como se encontra o financeiro da mesma organização. Cabe ressaltar ainda que os estudos de Silva (2012, p. 286) apontam que o conceito de índices de liquidez pode ser definido assim "Objetivam proporcionar um indicador do total capacidade que a organização possui em fazer o pagamento das suas dívidas, através da realização de comparações entre os direitos realizáveis e as exigibilidades".

Já os índices de endividamento devem ser associados com a quantidade do que a organização apresenta de dívidas. Situação em que os índices de rentabilidade com a capacidade da instituição em poder gerar lucro. Devemos afirmar ainda que "a rentabilidade é medida em função dos investimentos. As fontes de financiamento do Ativo são Capital Próprio e Capital de Terceiros. A administração adequada do Ativo proporciona maior retorno para a empresa" (Marion, 2007 p. 141). Todos os dados que são gerados através das referidas análises financeiras devem ser direcionados aos gestores, apontando assim como a organização está no contexto financeiro, com o intuito de assim ser capaz de fazer investimentos ou pensar em novos procedimentos para o negócio.

\section{Metodologia}

Metodologicamente, foi feita uma análise bibliométrica por meio de uma revisão sistemática de literatura, onde foram utilizados artigos do Portal periódicos CAPES do MEC, dos últimos dois anos, revisados por pares, foram selecionados 12 (doze) artigos da base SCOPUS (ELSEVIER), onde foram feitas buscas sobre Contabilidade Gerencial. Foram analisados incialmente 12 (doze) artigos, apenas 06 (seis) artigos demonstraram relevância para o tema abordado, desses artigos foram extraídos seus objetivos e seus resultados de forma sistemática e ordenada.

O desenvolvimento dos objetivos desta pesquisa, utilizou-se uma abordagem de natureza qualitativa, possuindo característica bibliográfica exploratória, pois para o seu desenvolvimento, foi necessária uma revisão por meio da leitura de livros e artigos científicos comprovados cientificamente, assim como pesquisas em sítios oficiais, Leis, Decretos, legislação pertinente ao período atual para alcançar o tema proposto. (Almeida Gomes, Monteiro, \& Paulino, 2021)

Complementando, Minayo \& colaboradores (2002) dizem que pesquisa qualitativa trabalha com o universo de significados, motivos, aspirações, crenças, valores e atitudes, correspondendo a um espaço mais profundo das relações, dos processos e dos fenômenos, portanto não podem ser reduzidos à operacionalização de variáveis, como ocorre nos dados quantitativos. Dessa forma, as características de uma pesquisa qualitativa são a objetivação do fenômeno e a hierarquização das ações de descrever, compreender e explicar.

\section{Resultados e Discussão}

A Contabilidade gerencial é uma ferramenta de suma importância para um trabalho bem elaborado para uma boa qualificação na tomada de decisões, desta maneira utiliza-se de análise de dados, redução de gastos, planejamento financeiros e preservação de desperdícios, visão econômica. A principal função dela é facilitar o uso da informação, sendo ela concreta e segura para que se possa chegar à melhor decisão, poupando as empresas de chegarem à falência. Podemos confirmar essas afirmações com a análise dos 06 (seis) artigos selecionados segue abaixo a Tabela 1, com seus principais resultados e discussão. 
Tabela 1 - Artigos selecionados para a Revisão Sistemática e suas abordagens.

\begin{tabular}{|c|c|}
\hline Artigo & Objetivo \\
\hline $\begin{array}{l}\text { Beuren, I. M., \& Dos Santos, V. } \\
\text { (2019). }\end{array}$ & $\begin{array}{l}\text { Este estudo examina os reflexos } \\
\text { dos Sistemas de Controle } \\
\text { Gerencial (SCGs) habilitantes e }\end{array}$ \\
\hline $\begin{array}{l}\text { Sistemas de controle gerencial } \\
\text { habilitantes e coercitivos e } \\
\text { resiliência organizacional. }\end{array}$ & $\begin{array}{l}\text { coercitivos na resiliência } \\
\text { organizacional, nas dimensões } \\
\text { cognitiva, comportamental e } \\
\text { contextual. }\end{array}$ \\
\hline
\end{tabular}

Cardoso, V. R. d. S., Campos, L. A., O trabalho teve por fim identificar Dantas, J. A., \& Medeiros, O. R. d. a relação do índice de liquidez (2019).

Fatores relacionados a liquidez estrutural dos bancos no Brasil. (Artigo Original). estrutural (ILE) com variáveis macroeconômicas, características dos bancos e vigência do Acordo de Basileia III.
Carraro, W. B. W. H., Meneses, R., \& Brito, C. (2019).

Combinação de categorias de práticas de controle de gestão para o alto desempenho de start-ups.
Este estudo tem como objetivo examinar possíveis combinações de práticas de controle de gestão que possam levar a um alto desempenho em start-ups.
O ILE apresentou relação positiva com as variações da taxa de câmbio, reservas internacionais e depósitos compulsórios, além da rentabilidade, tamanho e especialidade principal das instituições. Foi encontrada relação negativa do ILE com as variáveis taxa básica de juros, risco-país, saldo da balança comercial, período de vigência do Acordo de Basileia III, tipo de controle do capital (público ou privado) e terem ou não capital aberto, com ações listadas na Bolsa de Valores, Mercadorias e Futuros de São Paulo (BM\&FBOVESPA). A validação da relação dessas variáveis explanatórias com o ILE fornece uma compreensão mais ampla dos riscos aos quais instituições financeiras estão expostas, contribuindo para a análise preventiva do risco de liquidez bancária - indicador antecedente de crises financeiras, de perda de confiança e de instabilidade econômica.

Para obtenção de alto desempenho, são necessários controles de gestão para Clientes, Estratégia, Sistemas de Informação, Desempenho, Riscos e Orçamento. As categorias Cliente e Orçamento apresentaram a maior consistência em atender a condição proposta. Além disso, os resultados geraram duas combinações de condições para o alto desempenho do lucro líquido.

A combinação de diferentes práticas de controle de gestão contribui para o sucesso do negócio, principalmente quando relacionado às práticas de estratégia da organização. $\mathrm{O}$ uso de ferramentas de controle gerencial torna-se uma prioridade para as empresas que desejam sucumbir aos desafios impostos pelas incertezas corporativas, especialmente em empresas start-up, garantindo o crescimento sustentável desses negócios.

$\begin{array}{ll}\text { Lunardi, M. A., da Silva Zonatto, V. } & \begin{array}{l}\text { Este estudo investiga os efeitos } \\ \text { intervenientes do envolvimento no } \\ \text { C., \& Nascimento, J. C. (2019). }\end{array} \\ \begin{array}{l}\text { trabalho, atitudes gerenciais e } \\ \text { compartilhamento de informações }\end{array} \\ \begin{array}{ll}\text { em natos do envolvimento no trabalho } \\ \text { compartilhamento de informação e } \\ \text { no desempenho de controllers no entre a participação } \\ \text { contexto orçamentánário. }\end{array} & \begin{array}{l}\text { gerencial de controladores de } \\ \text { empresas que operam no Brasil. }\end{array}\end{array}$

Os resultados mostraram que a participação orçamentária influencia positivamente o envolvimento no trabalho, o que apresentou influência direta e indireta no desempenho gerencial, mediada por atitudes gerenciais. $\mathrm{O}$ envolvimento no trabalho influencia as atitudes gerenciais dos controladores e sua disposição de compartilhar informações com os superiores. No entanto, o compartilhamento vertical de informações não tem influência direta no desempenho gerencial.

\begin{tabular}{|c|c|}
\hline $\begin{array}{l}\text { Lunardi, M. A., Da Silva Zonatto, V. } \\
\text { C., \& Nascimento, J. C. (2020). }\end{array}$ & $\begin{array}{l}\text { Analisar os efeitos cognitivos } \\
\text { mediadores do compartilhamento } \\
\text { de informações verticais no }\end{array}$ \\
\hline $\begin{array}{l}\text { Efeitos cognitivos mediadores do } \\
\text { compartilhamento de informação na } \\
\text { relação entre participação } \\
\text { orçamentária e } \\
\text { gerencial. }\end{array}$ & \begin{tabular}{llr} 
processo & \multicolumn{2}{c}{ orçamentário e na } \\
relação entre & participação \\
orçamentária e & desempenho \\
gerencial. & &
\end{tabular} \\
\hline
\end{tabular}

Oro, I. M., \& Lavarda, C. E. F. Analisar como ocorre a interface (2019).

Interface dos sistemas de controle gerencial com a estratégia e medidas de desempenho em empresa familiar. (SCGs) com a estratégia e medidas de desempenho em empresa familiar sob a ótica da Teoria Contingencial.
Como resultado, temos que a participação orçamentária influencia positivamente o compartilhamento de informação vertical, que apresentou influência positiva no desempenho gerencial. O compartilhamento de informações verticais resulta de efeitos cognitivos da participação orçamentária. Maiores níveis de compartilhamento de informação vertical refletem em menor ambiguidade de papéis e em melhor desempenho gerencial. Mesmo que os indivíduos com responsabilidade orçamentária percebam a existência de assimetria de informações no ambiente de trabalho, seus efeitos sobre o desempenho não são significativos.

Como resultado, observou-se que a gestão familiar concebida pelo proprietário controlador com visão empreendedora, o trabalho conjunto (pai e filhos) e os valores organizacionais oriundos da unidade familiar (sistemas de crenças) demonstraram particularidades da dualidade família-negócios que contribuíram para implementação da estratégia e uso de medidas de desempenho. O estudo revelou que os valores da família presentes na gestão se manifestam nos sistemas de crenças que moldam o uso dos SCGs e no comportamento estratégico da organização. 
Através dos resultados foi notório a necessidade e a importância de se utilizar as ferramentas na contabilidade gerencial dentro das empresas. A principal função dela é facilitar o uso da informação, sendo ela concreta e segura para que se possa chegar à melhor decisão, poupando as empresas de chegarem à falência.

\section{Considerações Finais}

As pesquisas realizadas para a execução deste trabalho nos permitiram observar que a obtenção de alto desempenho, são necessários controles de gestão para Clientes, Estratégia, Sistemas de Informação, Desempenho, Riscos e Orçamento. As categorias Cliente e Orçamento apresentaram a maior consistência em atender a condição proposta. Além disso, os resultados geraram duas combinações de condições para o alto desempenho do lucro líquido. A participação orçamentária influencia positivamente o compartilhamento de informação vertical, que apresentou influência positiva no desempenho gerencial.

O compartilhamento de informações verticais resulta de efeitos cognitivos da participação orçamentária. Maiores níveis de compartilhamento de informação vertical refletem em menor ambiguidade de papéis e em melhor desempenho gerencial. Mesmo que os indivíduos com responsabilidade orçamentária percebam a existência de assimetria de informações no ambiente de trabalho, seus efeitos sobre o desempenho não são significativos. Esses resultados contribuem para o entendimento dos efeitos cognitivos mediadores do compartilhamento de informações na relação entre participação e desempenho, revelando que os efeitos da participação no desempenho podem não ocorrer a partir de uma relação simples de causalidade, mas a partir de determinados condicionantes.

Conforme se pôde observar na explanação realizada ao longo desse trabalho, é notório o quanto é importante, que cada vez mais, as empresas transformem o planejamento financeiro em uma ferramenta estratégica presente no seu cotidiano, aliando o mesmo a gestão de custos. Compreende-se que as empresas necessitam realizar projeções de suas finanças, projeções, estratégias e seus fluxos de caixa e, se precisaram de mais capital, devem obtê-lo com a maior antecedência possível. Do mesmo modo, se forem gerar superávits, devem planejar um uso produtivo desse dinheiro.

Entendemos que o sistema empresarial, que não está imune às interferências do ambiente, precisa de informações concretas para que seus investimentos no mercado, bem como suas atitudes em relação a empresa, sejam realizados com eficiência e de forma a agregar valor para a empresa. Dessa forma, as empresas necessitam de pessoas com conhecimento nas diversas áreas componentes de uma organização como administração, contabilidade, recursos humanos, economia, finanças, e seja especializada em reunir informações básicas da empresa e dos ambientes na qual atua para elaborar estratégias e decidir o destino da empresa e dos investimentos.

Sugestões para trabalhos futuros, a expectativa é que surjam mais trabalhos que produzam evidências dos efeitos diretos e indiretos do envolvimento na relação entre a participação orçamentária e o desempenho gerencial, mediado por atitudes gerenciais em relação ao orçamento e a disposição de compartilhar informações com os superiores.

\section{Referências}

Almeida G. A. J., Monteiro, C. G. D. R., \& Paulino, Z. (2021). Contabilidade gerencial: a importância das ferramentas gerenciais contábeis nas microempresas. Brazilian Journal of Development, 7(6), 58937-58956. https://doi.org/10.34117/bjdv7n6-336.

Beuren, I. M., \& Dos Santos, V. (2019). Sistemas de controle gerencial habilitantes e coercitivos e resiliência organizacional. Revista Contabilidade $e$ Financas, 30(81), 307-323. https://doi.org/10.1590/1808-057x201908210.

BRASIL. (2007). Lei n ${ }^{\circ} 11.638$, de 28 de Dezembro. http://www.planalto.gov.br/ccivil_03/_ato2007-2010/2007/lei/111638.html> .

Braga, R. (1991). Análise avançada do capital de giro. Caderno de Estudos FIPECAFI, São Paulo, n. 3, p. 01-20.

Brealey, R A. (1998). Princípios de finanças empresariais. Lisboa: McGraw-Hill.

Cardoso, V. R. d. S., Campos, L. A., Dantas, J. A., \& Medeiros, O. R. d. (2019). Fatores relacionados a liquidez estrutural dos bancos no Brasil. (Artigo Original). Revista Contabilidade \& Financas, 30(80), 252. https://doi.org/10.1590/1808-057x201806350. 
Carraro, W. B. W. H., Meneses, R., \& Brito, C. (2019). Combining Categories of Management Control Tools for High Performance of Start-ups. Revista Brasileira de Gestao de Negocios (Brazilian Journal of Business Management), 21(4), 861. https://doi.org/10.7819/rbgn.v21i5.4022.

Catelli, A (Coord.). (2015). Controladoria: Uma abordagem da GECON. Atlas.

Coelho, C U. F; \& Lins, L. S.. (2010). Teoria da contabilidade: abordagem contextual, histórica e gerencial. Atlas.

Conselho Federal De Contabilidade, (CFC). Princípios de Contabilidade e Normas Brasileiras de Contabilidade. http://cfc.org.br .

Chiavenato, I. (2003). Introdução à teoria geral da administração: uma visão abrangente da moderna administração das organizações. (7. ed.). Elsevier.

Ferreira, J. A. S. (2007). Contabilidade de Custos. São Paulo: Pearson.

Franco, H. (1997). Contabilidade Geral. (23.ed.), Atlas.

Garrison, Ray H.; \& Noreen, Eric W. (2001). Contabilidade Gerencial. (9.ed.) LTC.

Gitman, L. J. (2004). Princípios de Administração Financeira. Addison Wesley.

Iudícibus, S. (2009). Análise de balanços. (11. ed.). Atlas, 254 p. CERTO

Iudícibus, S. (2010). Contabilidade Introdutória / equipe de professores da Faculdade de Economia, Administração e Contabilidade da USP; coordenação Sérgio de Iudícibus. (11. Ed.), Atlas, 352 p.

Lopes, A. B.; \& Martins, E. (2005). Teoria da contabilidade: uma nova abordagem. Atlas.

Lunardi, M. A., da Silva Zonatto, V. C., \& Nascimento, J. C. (2019). Effects of Job Involvement, Managerial Attitudes, and Information Sharing on Controllers Performance in the Budgetary Context. Revista Brasileira de Gestao de Negocios (Brazilian Journal of Business Management), 21(3), 540. https://doi.org/10.7819/rbgn.v21i3.4000.

Lunardi, M. A., Da Silva Zonatto, V. C., \& Nascimento, J. C. (2020). Efeitos cognitivos mediadores do compartilhamento de informacąõ na relacąõ entre participacąõ orcąmentária e desempenho gerencial. Revista Contabilidade e Finanças, 31(82), 14-32. https://doi.org/10.1590/1808-057x201908610.

Martins, E. (2010) Contabilidade de Custos. (10. ed.) Atlas.

Marion, J. C et al (Coord.). (2003) Mudanças nas demonstrações contábeis: projeto nº3.641 e anteprojeto de reforma da lei das sociedades anônimas. Saraiva.

Marion, J. C. (2007). Análise das demonstrações contábeis: contabilidade empresarial. (3. ed.) Atlas.

Minayo, Maria Cecília De Souza; Deslandes, Suely Ferreira; Cruz Neto, Otávio; Gomes, Romeu. (2002). Pesquisa social: teoria, método e criatividade. (21.ed.) Petrópolis: Vozes.

Nascimento, Auster Moreira; \& Reginato Luciane. (2013). Controladoria: um enfoque na eficácia organizacional (3. ed.), Atlas

Oliveira, L. M.; Perez Jr., J. H.; \& Silva, C. A. S. (2014). Controladoria estratégica. Atlas.

Oro, I. M., \& Lavarda, C. E. F. (2019). Interface between management control systems and strategy and performance measures in a family business.(Original Article). Revista Contabilidade \& Finanças, 30(79), 14. https://doi.org/10.1590/1808-057x201806490.

Padoveze, C. L. Luís. (2009). Contabilidade Gerencial: Um enfoque em sistema de informação contábil. (6. ed.). Atlas.

Pizzolato, N. D. (2000). Introdução à Contabilidade Gerencial. (2 ed rev. e ampl.) Makron Books.

Porter, M E. (1998). (Org.) Estratégia: a busca da vantagem competitiva. Campus, p. 419-440.

Prestes, N. B. (2002). Planejamento estratégico como apoio à gestão empresarial. Análise, Porto Alegre, 13(1), 143-160.

Ross, S A., Werterfield, R W., Jordam, B D. (1998). Princípios de Administração Financeira. Atlas

Sá, A. L. Fundamentos da contabilidade geral. (3. ed.). Juruá, 2008.

Schmidt, P; Santos, J. 1.; \& Martins, M. A. S. (2014). Manual de controladoria. Atlas.

Stoner, J. A. F.; \& Freemann, R. E. (1985). Administração. (5. ed.). Prentice-Hall do Brasil. 